\title{
JEZLER, Peter, Himmel, Hölle, Fegefeuer. Das Jenseits im Mittelalter (Katalog des Schweizerischen Landesmuseums)
}

Joseph Morsel

\section{OpenEdition}

Édition électronique

URL : http://journals.openedition.org/ifha/1985

DOI : 10.4000/ifha. 1985

ISSN : 2198-8943

\section{Éditeur}

IFRA - Institut franco-allemand (sciences historiques et sociales)

Référence électronique

Joseph Morsel, « JEZLER, Peter, Himmel, Hölle, Fegefeuer. Das Jenseits im Mittelalter (Katalog des Schweizerischen Landesmuseums) », Revue de l'IFHA [En ligne], Date de recension, mis en ligne le 01 janvier 1994, consulté le 22 septembre 2020. URL : http://journals.openedition.org/ifha/1985 ; DOI https://doi.org/10.4000/ifha. 1985

Ce document a été généré automatiquement le 22 septembre 2020.

(C)IFHA 


\title{
JEZLER, Peter, Himmel, Hölle, Fegefeuer. Das Jenseits im Mittelalter (Katalog des Schweizerischen Landesmuseums)
}

\author{
Joseph Morsel
}

1 Les années 1980 ont vu la popularisation des travaux sur l'histoire de la mort, profondément renouvelée dans la décennie précédente par les recherches d'Ariès, Vovelle, Le Goff, Chiffoleau, etc. Et c'est d'ailleurs de 1986 que date le projet de cette exposition sur l'Au-delà médiéval, réalisée d'abord au (et par le) Landesmuseum de Zurich en 1993, puis remontée au Schnütgen-Museum de Cologne en 1994 - Zurich faisant ainsi office de "pont" entre France et Allemagne, si l'on considère que la problématique de la mort a plutôt circulé de la première à la seconde (ce qui apparaît clairement dans le décalage chronologique des ouvrages français et allemands figurant dans la riche bibliographie qui clôt le catalogue) et que la Suisse représente un creuset où se fondent les deux traditions historiographiques.

2 Le médiéviste français devrait donc se garder de considérer a priori cette exposition (et son catalogue) comme une simple excroissance de ce qui s'est fait en France. Outre le fait que les objets exposés proviennent presque sans exception d'un espace en général mal connu de lui (l'espace germanique, et notamment la Suisse orientale), pour lequel il dispose désormais d'un corpus (bien reproduit) d'images (sans parler des représentations schématiques remarquablement claires des diverses conceptions de l'Au-delà, p.14 et 19), il a également la possibilité d'appréhender, à travers les contributions qui composent la moitié du catalogue, les commentaires des objets exposés et la bibliographie, les approches spécifiques de la recherche allemande (par exemple sur la memoria dont il est question dans les trois ouvrages qui précédent).

Quinze contributions ouvrent le catalogue: une introduction aux représentations et préoccupations de l'Au-delà; la genèse de la théologie de l'Enfer; la soif des morts et sa satisfaction avant le Jugement Dernier; la représentation du Ciel; les connotations 
sociales du Purgatoire; les représentations du Purgatoire à travers les rites funéraires; la mort et l'Au-delà dans la littérature médiévale; le sein et le lait de la Vierge comme figures de l'intercession et du rachat; l'usage des livres d'heures; la représentation des élites urbaines comme fondateurs à la fin du Moyen Age; les relations entre pastorale et médecine, entre soin des âmes et soin des corps; le Purgatoire et les revenants chez les Vaudois d'après le registre d'Inquisition de Jacques Fournier; les aspects économiques (rentes et mainmorte) de l'économie du Salut; l'autel des morts à Bologne à l'époque moderne; la mort en Suisse du XIXe s. à nos jours.

4 Ces contributions sont suivies de la présentation et du commentaire de près de 200 objets exposés, puis d'un glossaire, enfin d'une riche bibliographie. Un ouvrage à connaître.

5 Joseph MORSEL 